\begin{tabular}{|c|c|}
\hline Postprint Version & 1.0 \\
\hline Journal website & http://linkinghub.elsevier.com \\
\hline Pubmed link & $\begin{array}{l}\text { http://www.ncbi.nlm.nih.gov/entrez/query.fcgi? } \mathrm{cmd}=\text { Retrieve\&db=pubmed\&dop } \\
\mathrm{t}=\mathrm{Abstract} \& \text { list uids=15488255\&query } \mathrm{hl}=20 \text { \&itool=pubmed docsum }\end{array}$ \\
\hline
\end{tabular}

* Corresponding author. Tel.: +31-30-272-9836x700; fax: +31-30-272-9729. E-mail address: a.volkers@nivel.nl (A.C. Volkers).

\title{
The problem of diagnosing major depression in elderly primary care patients
}

\author{
Anita C. Volkers*, Jasper Nuyen, Peter F.M. VerhaAK, FranÇOIS G. SCHElleVis \\ NIVEL (Netherlands Institute for Health Services Research), Drieharingstraat 6, PO box 1568, \\ 3500 NB Utrecht, Netherlands
}

\begin{abstract}
Background: To clarify the problem of diagnosing major depression in elderly primary care patients, we studied the nuances of diagnostic classification by general practitioners (GPs) and the relationship between sociodemographic and clinical factors and an accurate diagnosis of depression. Methods: As part of a national survey of general practice a standardised psychiatric interview (CIDI) was performed in 237 subjects z55 years screened for the presence of psychopathology. Fifty-five patients were found to suffer from a major depressive disorder in the last 12 months. In these patients, GPs registered during 1 year all contact diagnoses and prescriptions of medication. Results: Nearly all depressed patients $(96.4 \%)$ had one or more contacts with their GP during 1 year. GPs classified $20.8 \%$ of the patients as having a down/depressed feeling or depression, while $32.1 \%$ as having other psychological problems than depression. It was remarkable that an accurate diagnosis by GPs was significantly related to higher age in this age group. Regarding the clinical characteristics, there was a significantly higher number of prescriptions of antidepressants in the accurately diagnosed patients. We found no significant differences in respect to other clinical characteristics (e.g. severity and number of symptoms, comorbidity of anxiety and somatic disorders). Conclusions: GPs are aware of the psychological problems in half of the elderly patients with major depression, but do not explicitly distinguish depressive symptoms from other psychological problems or from social problems. Integrated programs may be more promising to improve the diagnostic rate than clinical education or guideline implementation alone.
\end{abstract}

\section{INTRODUCTION}

Half to one third of primary care patients with a major depressive disorder (according to a standardised psychiatric interview) are recognised as depressed cases by their general practitioner (GP) (Docherty, 1997; Tiemens et al., 1999). Underrecognition and underdiagnosing of depression is assumed to be more salient in elderly primary care patients (Bowers et al., 1990; Iliffe et al., 1991; Van Marwijk et al., 1996). In the Dutch community the 1-month prevalence of major depressive disorder (DSM-III criteria) between 55 and 85 years is 2\% (Beekman et al., 1995). 
Sociodemographic factors such as younger age and female sex and clinical characteristics such as severe depression and comorbidity of anxiety disorders are suggested to be related to a higher diagnostic rate in depressed patients, while the diagnostic rate may be decreased in case of comorbidity of somatic diseases (Coyne et al., 1995; Kirmayer et al., 1993; Thompson, 2001; Tiemens et al., 1996, 1999; Tylee et al., 1995). The role of these factors may change in late life depression. Less is known about the influence of somatic and psychiatric comorbidity on an accurate diagnosis in this age group. Neurological disorders like dementia and Parkinson's disease, cardiovascular diseases like stroke, cancer and metabolic and endocrine disorders are related to depression and may distract the attention from depressive symptoms when consulting a GP (Katona, 1994; Schwenk, 2002; Yesavage, 1992). At the same time, the use of antidementia drugs, drugs for Parkinson's disease, antiepileptic drugs and drugs for cardiovascular diseases with mood changing (side-) effects may mask depression (Farmacotherapeutisch Kompas, 2002/2003; Psychotropics 2000/2001; Unützer, 2002; Yesavage, 1992).

The aim of the present study was to obtain insight in the way GPs diagnose elderly patients $\geq 55$ years with a major depressive disorder and to identify which sociodemographic and clinical factors are related to an accurate diagnosis by GPs.

\section{METHODS}

Data of this study were obtained from the second Dutch National Survey of General Practice (DNSGP-2) (Schellevis et al., 2003). The DNSGP-2 was carried out in 104 general practices in The Netherlands. GPs registered all contacts with their patients in each practice during 1 calendar year (2001). A random sample $(n=1279)$ of the total practice population $(n= \pm 390,000)$, including 2480 patients $\geq 55$ years, participated in an extensive health interview survey with a response rate of $64.5 \%$. Responders and nonresponders did not differ regarding age and gender, but educational level was slightly higher in the responders. As part of this interview, patients $\geq 18$ years completed two screeners for psychopathology; the General Health Questionnaire 12-item version (GHQ-12) (Goldberg, 1972; Koeter and Ormel, 1991) for non-psychotic psychopathology and the CAGE questionnaire for alcoholism (Ewing, 1984; Mayfield et al., 1974). The validity of the GHQ as a screening instrument in general health care is high (sensitivity $83.4 \%$ and specificity $76.3 \%$ ) (Goldberg et al., 1997). A sum score of 4 on the CAGE assured (100\%) the presence of alcoholism. If patients had a GHQ score $z 4$ (first half of the year) or $\geq 3$ (second half of the year) ${ }^{1}$ and/or the maximum sum score of 4 on the CAGE questionnaire, they were asked for participation in a standardised psychiatric interview (12month Composite International Diagnostic Interview (CIDI) version auto 2.1) (WHO, 1997). In the age group $\geq 55$ years, the CIDI was actually performed in 237 of the 413 patients (response rate $57.4 \%$ ) and there were no differences in age, gender, educational level, ethnicity, GHQ and CAGE score between responders and non-responders. In this study, we included the 55 patients $\geq 55$ years who fulfilled the DSM-IV criteria (American Psychiatric Association, 1994) for major depressive disorder $(14$ males and 41 females; mean age $( \pm$ S.D. $)=63.6( \pm 7.8))$.

GPs registered during each contact with a patient the contact diagnosis in an electronic medical record coded according to the International Classification of Primary Care-1 (ICPC) (Lamberts and Wood, 1987). In case of the presence of depressive symptoms, GPs could register the symptom/complaint code P03 'down/depressed feelings' or the disease code P76 'depression'. The ICPC definition of depression (P76) is based on the criteria stated in the International Classification of Health Problems in Primary Care (ICHPPC-2-defined) (WONCA, 1983).

Sociodemographic factors (age, gender and educational level) were derived from the health interview survey. Regarding the clinical characteristics, CIDI data were used to determine severity of depression, number of depressive symptoms and comorbidity of anxiety disorders. The GHQ score was taken into account as an additional variable for severity of psychopathology. Comorbidity of somatic diseases was determined by the presence of an ICPC diagnosis on disease level. The prescription for antidepressants, other drugs acting on the nervous system, and drugs for other diseases than depression with mood changing (side-) effects was derived from the drug prescription registration by GPs.

\footnotetext{
${ }^{1}$ The GHQ threshold was lowered during the registration period to enlarge the intake of participants.
} 
Differences in sociodemographic and clinical factors between patients with and without an ICPC diagnosis P03 and/of P76 were tested by Student's $t$-tests in case of normally distributed factors, M-W $U$-tests in case of non-parametric ordinal variables and by Chi-square $\left(\chi^{2}\right)$ analyses in case of dichotomous factors. $P$ values $\leq 0.05$ were regarded as significant.

\section{RESULTS}

Fifty-three patients (96.4\%) had one or more contacts with their GP in the contact registration. In 11 of these patients GPs registered the diagnostic codes P03 and/or P76 resulting in an overall diagnostic rate of 20.8\% (Table 1). Furthermore, in 17 patients (32.1\%) GPs registered ICPC codes for other psychological problems than depression. The most frequent registered psychological problems were anxiety at complaint and disease level (P01/P74) (five patients) and sleep complaints (P06) (four patients).

Patients who were accurately diagnosed were significantly older than patients without this classification ( $T$-test, $P \leq 0.05$ ), but gender and educational level did not differ significantly between the patient groups. Regarding the clinical factors, no significant differences were found for the GHQ score, number of depressive symptoms and severity of depression. More than half of the patients $(n=$ 30 ) had also an anxiety disorder CIDI. Although comorbidity of anxiety disorders tended to be higher in the accurately diagnosed group (72.7\%) in comparison to the nonaccurately diagnosed group $(52.4 \%)$, this difference failed to reach significance. In both patient groups there was a high comorbidity of somatic illness; $81.8 \%$ in the accurately diagnosed patients and $92.9 \%$ in the nonaccurately diagnosed patients. The prevalence of somatic comorbidity was not significantly different between patient groups. In additional analyses this was also found for comorbidity of cardiovascular and respiratory diseases and the prevalence of general and unspecified diseases.

Antidepressants were prescribed significantly more often in patients with a GP diagnosis (72.7\%) than in patients without a GP diagnosis $(28.6 \%)$. This was not the case for other drugs acting on the nervous system or other drugs with mood changing (side-) effects.

\section{DISCUSSION}

In the present study, $20.8 \%$ of the patients older than 55 years with a major depression in the last 12 months were classified by their GP as having a down/ depressed feeling (P03) and/or a depression (P76). The 1 year registration period provided the possibility to follow depressive episodes in their entire course. This methodological design overcomes the criticism on studies investigating the diagnostic rate at one point of time. Nevertheless, the diagnostic rate of major depression was comparable with the low recognition rates previously reported. Unfortunately, we did not know if and how patients presented their complaints, e.g. somatisation of depressive symptoms, during the consultation.

The percentage of patients classified as having other psychological problems than depression (32.1\%) was in agreement with the percentage of 33.3\% found by Tiemens et al. (1999). In additional analysis we found that also $13.2 \%$ of the depressed patients was misclassified as having social problems. The misclassification of depression in non-medical terms should not be overlooked in the older age group.

Due to the two-stage sampling of patients the overall response rate was much lower than the response rates to the health interview and CIDI separately. The average GHQ score was similar in responders and non-responders, but the GHQ provides no specific information about similarity of psychiatric morbidity between responders and non-responders. Therefore, a selection bias of patients cannot be ruled out. The number of patients may have contributed to the finding that clinical differences between the patients groups did not reach significance.

Age was higher in the accurately diagnosed patients. However, our preliminary data of younger patients, showed that the present study sample had a diagnostic rate some percentages lower than patients between 18 and 55 years. The relationship between age and diagnostic rate of major depression may not be a linear one.

After more than one decade of clinical education and guideline implementation GPs still have difficulties to differentiate depression from other psychological problem and social problems in old age. Recently, integrated quality improvement programs focusing on both improvement of recognition 
and treatment have shown more promising results regarding improvement of clinical outcome (Callahan, 2001; NHS Centre, 2002). New strategies including at the same time education of patients, family and public and the organisation of care may facilitate diagnosing depression in the elderly by GPs.

\section{ACKNOWLEDGEMENTS}

Financial support by ZonMw "Netherlands Organisation for Health Research and Development" for this study is gratefully acknowledged.

\section{TABLES}

Table 1

ICPC diagnostic classification by GPs in patients with a major depressive disorder and one or more GP contacts $(n=53)$

\begin{tabular}{lll}
\hline & $\begin{array}{l}\text { Diagnostic } \\
\text { rate }\end{array}$ & $\begin{array}{l}\text { Cumulative } \\
\text { diagnostic } \\
\text { rate }\end{array}$ \\
\hline
\end{tabular}

P03

Number of GP contacts $\quad 18$

Number of patients 4

P76

Number of contacts $\quad 26$

Number of patients 9

Total P03 and/or P76

Number of contacts 44

Number of patients $\quad 11(20.8 \%) \quad 11(20.8 \%)$

Other P code than P03 and/or P76

\begin{tabular}{lll} 
Number of patients & $17(32.1 \%)$ & $28(52.9 \%)$ \\
\hline
\end{tabular}

P, psychic problems; P03, down/depressed feeling; P76, depression.

\section{REFERENCES}

American Psychiatric Association, 1994. Diagnostic and Statistical Manual of Mental Disorders, 4th ed. APA, Washington, DC.

Beekman, A.T., Deeg, D.J., van Tilburg, T., Smit, J.H., Hooijer, C., van Tilburg, W., 1995. Major and minor depression in later life: a study of prevalence and risk factors. J. Affect. Disord. 24,36 (1-2), $65-75$.

Bowers, J., Jorm, A.F., Henderson, S., Harris, P., 1990. General practitioners' detection of depression and dementia in elderly patients. Med. J. Aust. 153 (4), 192- 196.

Callahan, C.M., 2001. Quality improvement research on late life depression in primary care. Med. Care 39 (8), 772- 784.

Coyne, J.C., Fechner-Bates, S., Schwenk, T.L., 1994. Prevalence, nature, and comorbidity of depressive disorders in primary care. Gen. Hosp. Psychiatry 16 (4), 267- 276.

Docherty, J.P., 1997. Barriers to the diagnosis of depression in primary care. J. Clin. Psychiatry 58 (Suppl. 1), $5-10$.

Ewing, J.A., 1984. Detecting alcoholism. The CAGE questionnaire. J. Am. Med. Assoc. 12,252 (14), 1905- 1907.

Farmacotherapeutisch Kompas 2002/2003. College voor zorgverzekeringen (cvz).

Goldberg, D.P., 1972. The Detection of Psychiatric Illness by Questionnaire. Maudsley Monograph, vol. 21. Oxford University Press, London. 
Goldberg, D.P., Gater, R., Sartorius, N., Ustun, T.B., Piccinelli, M., Gureje, O., Rutter, C., 1997. The validity of two versions of the GHQ in the WHO study of mental illness in general health care. Psychol. Med. 27 (1), 191-197.

Iliffe, S., Haines, A., Gallivan, S., Booroff, A., Goldenberg, E., Morgan, P., 1991. Assessment of elderly people in general practice. 1. Social circumstances and mental state. Br. J. Gen. Pract. 41 (342), 912.

Katona, C.L.E., 1994. Depression in Old Age Wiley, England.

Kirmayer, L.J., Robbins, J.M., Dworkind, M., Yaffe, M.J., 1993. Somatization and the recognition of depression and anxiety in primary care. Am. J. Psychiatry 150 (5), 734-741.

Koeter, M.W.J., Ormel, J., 1991. General Health QuestionnaireNeederlandse Bewerking en Handleiding. Swets and Zeitinger, Lisse, The Netherlands.

Lamberts, H., Wood, W., 1987. ICPC International Classification of Primary Care Oxford University Press, Oxford.

Mayfield, D., McLeod, G., Hall, P., 1974. The CAGE questionnaire: validation of a new alcoholism screening instrument. Am. J. Psychiatry 131 (10), 1121- 1123.

NHS centre for reviews and dissemination, 2002. Improving the recognition and management of depression in primary care. Eff. Health Care 7 (5), 1- 12.

Psychotropics, 2000/2001. Lundbeck, Hermann \& Fisher, Denmark.

Schellevis, F.G., Westert, G.P., De Bakker, D.H., Groenewegen, P.P., Van der Zee, J., Bensing, J.M., 2003. De tweede nationale studie naar ziekten en verrichtingen in de huisartspraktijk: aanleiding en methoden. Huisarts Wet. 46 (1), $7-12$.

Schwenk, T.L., 2002. Diagnosis of late life depression: the view from primary care. Biol. Psychiatry 52 (3), 157- 163.

Thompson, C., Ostler, K., Peveler, R.C., Baker, N., Kinmonth, A.L., 2001. Dimensional perspective on the recognition of depressive symptoms in primary care: the Hampshire Depression Project 3. Br. J. Psychiatry 179, 317- 323.

Tiemens, B.G., Ormel, J., Simon, G.E., 1996. Occurrence, recognition, and outcome of psychological disorders in primary care. Am. J. Psychiatry 153 (5), 636-644.

Tiemens, B.G., Von Korff, M., Lin, E.H., 1999. Diagnosis of depression by primary care physicians versus a structured diagnostic interview. Understanding discordance. Gen. Hosp. Psychiatry 21 (2), 87-96.

Tylee, A., Freeling, P., Kerry, S., Burns, T., 1995. How does the content of consultations affect the recognition by general practitioners of major depression in women? Br. J. Gen. Pract. 45 (400), $575-578$.

Unützer, J., 2002. Diagnosis and treatment of older adults with depression in primary care. Biol. Psychiatry 52 (3), 285- 292.

Van Marwijk, H.W., De Bock, G.H., Hermans, J., Mulder, J.D., Springer, M.P., 1996. Prevalence of depression and clues to focus diagnosis. A study among Dutch general practice patients $65+$ years of age. Scand. J. Prim. Health Care 14 (3), 142-147.

WHO, 1997. Composite International Diagnostic Interview (CIDI). Basis versie 2.1, 12 maanden, Red. Ter Smitten MH, Smeets RMW, Van den Brink W.

WONCA Classification Committee, 1983. ICHPPC-2-Defined Inclusion Criteria for the Use of the Rubrics of the International Classification of Health Problems in Primary Care. Oxford University Press, Oxford.

Yesavage, J.A., 1992. Depression in the elderly. How to recognize masked symptoms and choose appropriate therapy. Postgrad. Med. 91 (1), 255-258, 261. 